\title{
FUNGOS MICORRÍZICOS ARBUSCULARES E ADUBAÇÃO FOSFATADA NO CRESCIMENTO INICIAL DE SEIS ESPÉCIES ARBÓREAS DO CERRADO ${ }^{1}$
}

\author{
Kenia Alves Pereira Lacerda², Marcelle Moreira de Souza Silva³, Marco Aurélio Carbone Carneiro 4 \\ Edésio Fialho dos Reis ${ }^{5}$, Orivaldo José Saggin Júnior ${ }^{6}$
}

(recebido: 21 de julho de 2009; aceito: 27 de maio de 2011)

RESUMO: Conduziu-se este estudo, com o objetivo de avaliar o benefício da inoculação com o fungo micorrízico arbuscular, Glomus clarum, sobre o crescimento inicial da gabiroba (Campomanesia cambessedeana), baru (Dipterix alata), jatobá (Hymenaea courbaril), ingá (Inga laurina), caroba (Jacaranda cuspidifolia) e chichá (Sterculia striata), espécies arbóreas nativas do Bioma de Cerrado, em solo não esterilizado com baixo $\left(0,02 \mathrm{mg} \mathrm{L}^{-1}\right)$ e alto $\left(0,2 \mathrm{mg} \mathrm{L}^{-1}\right)$ teor de $\mathrm{P}$ na solução do solo. Os experimentos foram conduzidos em casa de vegetação, em vasos de $1,5 \mathrm{~kg}$, por até 120 dias. O delineamento experimental para cada espécie arbórea foi inteiramente casualizado com dez repetições, em esquema fatorial 2x2 (mudas inoculadas e não inoculadas e dois níveis fósforo (P) na solução do solo). As plantas arbóreas do Cerrado apresentaram incremento na colonização micorrízica pela inoculação com Glomus clarum, exceto o chichá que apresentou colonização da comunidade indígena alta não diferindo da promovida pelo fungo inoculado. A inoculação proporcionou aumento no crescimento do baru, gabiroba, ingá, caroba e chichá, assim como da matéria seca da parte aérea (MSPA) e a matéria seca de raízes (MSR), sendo que, para a caroba, o efeito foi sinérgico com a aplicação de P ao solo. O baru e o jatobá apresentaram apenas incremento da matéria seca com à aplicação de $\mathrm{P}$ ao solo. A micotrofia (dependência micorrízica) das espécies e suas respostas à inoculação e ao fósforo são discutidas. Recomenda-se para produção de mudas, de qualidade, de caroba, gabiroba, chichá e ingá a inoculação com Glomus clarum conjuntamente com a fertilização fosfatada do solo e para o jatobá e baru apenas aplicação de P ao solo.

Palavras-chave: Mudas, revegetação, inoculação, simbiose, fósforo.

\section{EFFECT OF ARBUSCULAR MYCORRHIZAL FUNGI AND PHOSPHATE FERTILIZATION ON INITIAL GROWTH OF SIX ARBOREAL SPECIES OF CERRADO}

\begin{abstract}
This study evaluated the benefit of inoculation with arbuscular mycorrhizal fungi, Glomus clarum, for the initial growth of some native arboreal species of the Cerrado biome, namely gabiroba (Campomanesia cambessedeana), baru (Dipterix alata), jatobá (Hymenaea courbaril), ingá (Inga laurina), caroba (Jacaranda cuspidifolia) and chichá (Sterculia striata), in unsterilized soil with low (0.02 $\left.\mathrm{mg} \mathrm{L}^{-1}\right)$ and high $\left(0.2 \mathrm{mg} \mathrm{L}^{-1}\right)$ concentrations of $P$ in the soil solution. Experiments were conducted in a greenhouse, using $1.5 \mathrm{~kg}$ vases, for up to 120 days. The experimental design for each arboreal species was completely randomized, with ten replicates in a $2 \times 2$ factorial design (inoculated and noninoculated seedlings, and two levels of phosphorus ( $P$ ) in the soil solution). Arboreal plants of the Cerrado biome showed increased mycorrhizal colonization from inoculation with Glomus clarum, except chichá, as this species showed a high indigenous colonization, not differing from the colonization promoted by inoculated fungi. Inoculation promoted increased growth in baru, gabiroba, ingá, caroba and chichá, increasing shoot dry matter (MSPA) and root dry matter (MSR). In caroba, this effect was synergistic with application of P to the soil. Baru and jatobá showed increased dry matter with application of $P$ to the soil only. The mycotrophy (mycorrhizal dependence) of species and their response to inoculation and to phosphorus are discussed. In order to produce quality seedlings of caroba, gabiroba, chichá and ingá, combining inoculation with Glomus clarum and phosphate fertilization of the soil is recommended, while for jatobá and baru only the application of P to the soil is recommended.
\end{abstract}

Key words: Seedlings, revegetation, inoculation, symbiosis, phosphorus.

'Extraído da Dissertação de Mestrado apresentado pela primeira autora à Universidade Federal de Goiás/Campus Jataí

${ }^{2}$ Bióloga, Professora Mestre em Agronomia (Produção Vegetal) - Instituto Federal de Ensino de Jataí - Rua Riachuelo, 2090 - Samuel Graham Jataí, GO - 75.800-00 - keniaapl@bol.com.br

${ }^{3}$ Acadêmica de Engenharia Agronômica - Universidade Federal de Goiás/UFG - Campus Jataí - BR 364, km 192 - 75.800-000 - Jataí, GO marcelleagro@hotmail.com

${ }^{4}$ Engenheiro Agronômo, Professor Dr. em Ciência do Solo - Universidade Federal de Goiás/UFG - Campus Jataí - BR 364, km 192 - 75.800 -000 Jataí, GO - carbonecarneiro@pq.cnpq.br

${ }^{5}$ Engenheiro Agrônomo, Professor Dr. em Genética e Melhoramento - Universidade Federal de Goiás/UFG - Campus Jataí - BR 364, km 192 75.800-000 - Jataí, GO - edesio7@brturbo.com.br

${ }^{6}$ Engenheiro Agrônomo, Pesquisador Dr. em Ciência do Solo - Embrapa Agrobiologia - BR 465, km 07 - Cx. P. 74505 - 23890-000 - Seropédica, RJ saggin@enpab.embrapa.br

Cerne, Lavras, v. 17, n. 3, p. 377-386, jul./set. 2011 


\section{INTRODUÇÃo}

Existe atualmente uma enorme demanda por tecnologia de recomposição florística, especialmente de matas nativas que foram destruídas. No entanto, das espécies de plantas nativas pouco se conhece das suas exigências nutricionais e relações ecológicas, como, por exemplo, sua capacidade de formar simbioses com fungos do filo Glomeromycota, as quais são denominadas de micorrizas arbusculares.

Para que seja estabelecida a simbiose entre fungos micorrízicos arbusculares (FMA) e a maioria das raízes de plantas superiores, há a necessidade de uma íntima interação entre esses simbiontes. Nessa associação, a planta é beneficiada pelo aumento de absorção de água e nutrientes, principalmente de $\mathrm{P}$, pelas hifas fúngicas $\mathrm{e}$ o fungo obtém da planta os fotoassimilados necessários para que se complete seu ciclo de vida (MOREIRA; SIQUEIRA, 2006). Portanto, os FMA são de grande importância para a estruturação das comunidades vegetais, pois alteram a capacidade competitiva entre as espécies vegetais, de acordo com a fertilidade do solo e sua dependência micorrízica (FLORES-AYLAS et al., 2003), influenciando grandemente o processo de revegetação de áreas degradadas, principalmente em solos com baixa concentração de fósforo, como é o caso da maioria dos solos tropicais.

Adicionalmente, os FMA conferem maior tolerância a estresses bióticos (pragas e patógenos do sistema radicular) e abióticos (estresse hídrico, presença de metais pesados e outros), aos quais as plantas estão sujeitas, principalmente logo após o transplante de mudas para o campo (SIQUEIRA et al., 1998). A inoculação com FMA no estágio de mudas proporciona uma maior taxa de sobrevivência dessas mudas em campo (CARNEIRO et al., 2004). Assim, é amplamente aceito que a micorrização das mudas favorece o seu crescimento inicial no viveiro e, posteriormente, o seu estabelecimento no campo, além de ser considerada essencial em programas de reflorestamento de áreas degradadas (FRANCO et al., 1995). Em programa de recuperação de matas ciliares no Estado de Minas Gerais, verificou-se que em torno de $90 \%$ das plantas avaliadas apresentaram colonização micorrízica em suas raízes e $20 \%$ eram altamente dependentes dessa simbiose (CARNEIRO et al., 1998).

O desconhecimento do potencial de uso dos recursos naturais e o desrespeito às leis ambientais têm provocado prejuízos irreparáveis à flora e ao solo, colocando muitas espécies vegetais em risco de extinção e gerando diversas áreas degradadas com baixo potencial de resiliência. Em virtude da expansão agrícola, grande parte do Bioma Cerrado foi incorporada ao processo produtivo, gerando áreas desprovidas de vegetação nativa, incapazes de serem recolonizadas pelas espécies nativas sem a intervenção do homem (JORDAN, 1991), aliado a poucas informações sobre espécies arbóreas de Cerrado, já que os estudos existentes concentram-se na região sul e sudoeste do Brasil (CARNEIRO et al., 1998; PASQUALINI et al., 2007; SIQUEIRA; SAGGIN JÚNIOR, 2001; ZANGARO et al., 2005).

Dessa forma, neste estudo objetivou-se avaliar o benefício da inoculação do fungo micorrízico arbuscular Glomus clarum sobre o crescimento inicial de ingá (Inga laurina), jatobá (Hymenaea courbaril), caroba (Jacaranda cuspidifolia), gabiroba (Campomanesia cambessedeana), baru (Dipterix alata) e chichá (Sterculia striata) representantes de espécies arbóreas nativas do Bioma de Cerrado, em um solo não esterilizado com baixo e alto teores de P.

\section{MATERIAL E MÉTODOS}

O estudo foi desenvolvido em casa de vegetação, na Universidade Federal de Goiás, Campus Jataí. O delineamento experimental foi inteiramente casualizado com dez repetições em esquema fatorial 2 x 2, constando da inoculação ou não com Glomus clarum Nicolson e Schenck, combinado com a aplicação de fósforo no solo para atingir 0,2 e $0,02 \mathrm{mg} \mathrm{L}^{-1}$ de $\mathrm{P}$ na solução do solo, considerado alto e baixo $\mathrm{P}$, respectivamente.

O solo utilizado foi um Latossolo Vermelho distroférrico, coletado em barranco (horizonte B, numa profundidade maior que $60 \mathrm{~cm}$ ), apresentando as seguintes características químicas e físicas: $\mathrm{pH}$ em água: 5,5; H+Al: $4,49 \mathrm{cmol}_{\mathrm{c}} \mathrm{dm}^{-3} ; \mathrm{Ca}: 0,37 \mathrm{cmol}_{\mathrm{c}} \mathrm{dm}^{-3} ; \mathrm{Mg}: 0,72$ $\mathrm{cmol}_{\mathrm{c}} \mathrm{dm}^{-3} ; \mathrm{K}: 22,40 \mathrm{mg} \mathrm{dm}^{-3}$; $\mathrm{P}: 1,37 \mathrm{mg} \mathrm{dm}^{-3}$; matéria orgânica: $14,61 \mathrm{~g} \mathrm{~kg}^{-1}$; argila: $651,1 \mathrm{~g} \mathrm{~kg}^{-1}$; silte: 47,8 $\mathrm{g} \mathrm{kg}^{-1}$ e areia: $301,1 \mathrm{~g} \mathrm{~kg}^{-1}$. O solo foi homogeneizado, seco, peneirado em malha de $4 \mathrm{~mm}$, corrigido com calcário para elevar a soma de bases a $50 \%$ e incubado por 15 dias umedecido. Em razão do solo não ter sido esterilizado, foram retiradas amostras para quantificar os FMA nativos presentes. Para isso, os esporos de FMA foram separados do solo por peneiramento úmido (GERDEMANN; NICOLSON, 1963), encontrando-se, em média, três esporos por $50 \mathrm{~mL}$ de solo que não foram identificados taxonomicamente.

Cerne, Lavras, v. 17, n. 3, p. 377-386, jul./set. 2011 
O solo foi acondicionado em sacos plásticos para mudas com capacidade de $1,5 \mathrm{~kg}$ e adubado, aplicandose solução nutritiva contendo $\mathrm{NaMoO}_{4}, \mathrm{CH}_{4} \mathrm{~N}_{2} \mathrm{O}, \mathrm{KCl}$, $\mathrm{H}_{3} \mathrm{BO}_{4}, \mathrm{ZnSO}_{4}$ e $\mathrm{CuSO}_{4}$, fornecendo 1,07; 85,71; 190,8; 72,06; 24,69 e 19,64 mg kg-1 de Mo, N, K, B, Zn, S e Cu, respectivamente. Essa fertilização aplicada foi repetida posteriormente aos 30 e 60 dias, após o transplante das espécies arbóreas para o solo.

Após a primeira fertilização, o solo foi incubado por um período de 15 dias e, posteriormente, foram estabelecidas as doses baixa $\left(0,02 \mathrm{mg} \mathrm{L}^{-1}\right)$ e alta $(0,2 \mathrm{mg}$ $\mathrm{L}^{-1}$ ) de fósforo na solução do solo, conforme preconizado por Habte e Manjunath (1991). Para isso, realizou-se um estudo preliminar, aplicando doses crescentes de superfosfato triplo $\left(41 \%\right.$ de $\left.\mathrm{P}_{2} \mathrm{O}_{5}\right)$ em amostras do solo, que foram incubadas úmidas por 15 dias. Após esse período, a solução do solo foi extraída com água por centrifugação, determinando-se as quantidades de superfosfato triplo necessárias para obter as concentrações desejadas de $\mathrm{P}$ na solução do solo, encontrando-se 40 e $80 \mathrm{mg}$ de $\mathrm{P}_{2} \mathrm{O}_{5}$ (super fosfato triplo) por amostra.

As espécies arbóreas estudadas foram Gabiroba, Baru, Jatobá, Ingá, Caroba e Chichá (Tabela 1), sendo suas sementes coletadas em dezembro a março de 2006/2007 na região do Sudoeste de Goiás. No plantio, essas sementes foram submetidas à desinfestação com hipoclorito de sódio $(0,5 \%)$ por 5 minutos. Em seguida, foram lavadas com água corrente e colocadas para germinar em bandejas com areia esterilizada em autoclave (1 atm por 1 hora, 1 hora de descanso e mais 1 hora de esterilização).

Após a germinação das plântulas, em torno de 7 dias, estas foram transplantadas para os sacos plásticos e no momento do transplante foi realizada a inoculação com Glomus clarum, aplicando $50 \mathrm{~mL}$ de solo-inóculo, contendo em torno de 300 esporos, além de outros propágulos como hifas e raízes colonizadas, obtidos em vaso de cultivo, utilizando como planta hospedeira a gramínea Brachiaria decumbens Stapf. Esse fungo havia sido anteriormente isolado do próprio solo utilizado neste estudo, sob pastagem de Brachiaria brizantha. Nos tratamentos sem inoculação, foram adicionados $50 \mathrm{~mL}$ de um filtrado do solo-inóculo ausente de esporos e outros propágulos do FMA.

Após a repicagem, as mudas foram mantidas em casa de vegetação por um período de 90 (baru) ou 120 (demais espécies) dias, variando com a velocidade de crescimento da espécie. Durante esse período, as mudas foram avaliadas quanto ao diâmetro do caule, próximo ao colo da planta, a cada 30 dias após o transplante. Ao final do período de condução, a parte aérea e as raízes foram cortadas, lavadas com água destilada, para a remoção de substrato e outras impurezas e, posteriormente, secas em estufa, de circulação forçada de ar, a $68^{\circ} \mathrm{C}$ até obter peso constante para a obtenção da matéria seca da parte aérea (MSPA) e das raízes (MSR).

Para a avaliação da colonização micorrízica, das raízes ainda frescas, foram retiradas amostras de $1 \mathrm{~g}$ de raízes finas, as quais foram acondicionadas em álcool $70 \%$ até sua clarificação e coloração. Para a clarificação foram utilizadas solução de $\mathrm{KOH}$ 2,5\% e posterior imersão em água oxigenada alcalina, conforme a metodologia modificada por Koske e Gemma (1989). Para a coloração, foi utilizado azul de anilina em glicerina acidificada, conforme Grace e Stribley (1991). As raízes coradas de cada amostra foram dispostas paralelamente em duas lâminas com glicerina, cobertas com lamínulas de 24x50 mm e observadas em microscópio óptico (200 x). Nesse aumento, o campo óptico do microscópio permitiu visualizar segmentos de raiz com comprimento de $1 \mathrm{~mm}$. Observaram-se 120 segmentos de raiz por amostra e avaliou-se a porcentagem total de segmentos colonizados (MCGONIGLE et al., 1990).

Tabela 1 - Relação e classificação das espécies arbóreas estudadas.

Table 1 - List and classification of the arboreal studied species.

\begin{tabular}{lcccc}
\hline Nome comum & Espécie & Ordem & Família & PMS $^{1}(\mathrm{~g})$ \\
\hline Gabiroba & Campomanesia cambessedeana O.Berg & Myrtales & Myrtaceae & 0,02 \\
Baru & Dipterix alata Vogel & Fabales & Fabaceae & 4,00 \\
Jatobá & Hymenaea courbaril L. & Fabales & Fabaceae & 4,00 \\
Ingá & Inga laurina (Sw.) Willd. & Fabales & Fabaceae & 1,30 \\
Caroba & Jacaranda cuspidifolia Mart. & Lamiales & Bignoniaceae & 0,03 \\
Chichá & Sterculia striata St. Hil. \& Naud. & Malvales & Malvaceae & 3,00 \\
\hline
\end{tabular}

1. PMS - peso médio da semente.

Cerne, Lavras, v. 17, n. 3, p. 377-386, jul./set. 2011 
Com os dados de matéria seca da parte aérea, calculou-se a resposta a inoculação com Glomus clarum em cada nível de $\mathrm{P}$, com base na fórmula $100[(\mathrm{X}-\mathrm{Y}) / \mathrm{X}]$, onde $\mathrm{X}$ é a massa da planta inoculada e $\mathrm{Y}$ a massa da planta não inoculada (PLENCHETE et al., 1983).

As variáveis analisadas foram submetidas à análise de variância e as médias comparadas entre si pelo teste de Tukey a 5\% de significância, utilizando-se o programa Sistema de Análises Estatísticas e Genéticas (SAEG).

\section{RESULTADOS E DISCUSSÃO}

As plantas arbóreas que foram avaliadas no presente estudo mostraram incremento na colonização micorrízica decorrente da inoculação com Glomus clarum (Figura 1), sendo que não houve efeito do fator $\mathrm{P}$ e nem da interação, exceção ao chichá que não foi significativo para nenhum dos fatores estudados. Os poucos esporos de FMA indígenas recuperados do solo antes da condução do experimento (três esporos por $50 \mathrm{~mL}$ de solo) foram capazes de promover colonizações micorrízicas consideradas elevadas (maiores que 50\%) para o caso do ingá e do chichá, sendo que, nessa última, a colonização da comunidade indígena não diferiu da promovida por Glomus clarum. A presença de colonização micorrízica nas plantas, associada ao incremento promovido pela inoculação, indica grau de micotrofia (dependência micorrízica), podendo este ser baixo ou elevado, dependendo das características genéticas de cada espécie (SIQUEIRA; SAGGIN JÚNIOR, 2001) como será discutido adiante.

O diâmetro do caule, das plantas avaliadas não apresentou efeito do fósforo aplicado ao solo e nem da interação entre P e FMA. Houve efeito significativo somente para inoculação micorrízica (Figura 2). A inoculação de Glomus clarum aumentou o diâmetro do caule a partir dos 60 dias do transplante para o barú e de 90 dias para chichá, caroba, ingá e gabiroba. Já, para o jatobá não se constatou diferença significativa $(p \leq 0,05)$ em nenhum dos fatores estudados.

A ausência de resposta no período inicial de crescimento é atribuída às próprias reservas nutricionais contidas nas sementes, ao tempo necessário para o estabelecimento da simbiose funcional, às diferenças de conformação do sistema radicular e à própria condição de micotrofia (dependência micorrízica) da planta, como verificado em vários estudos, em outras condições e ambientes, no Brasil e no exterior (ALLSSOP; STOCK, 1995; PASQUALINI et al., 2007; SIQUEIRA et al., 1998; ZANGARO et al., 2005).

Cerne, Lavras, v. 17, n. 3, p. 377-386, jul./set. 2011

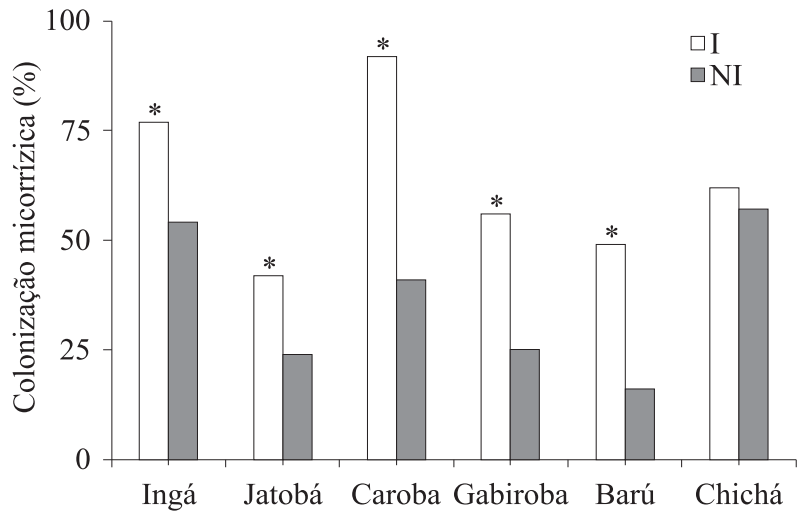

Figura 1 - Colonização micorrízica de espécies arbóreas do Cerrado inoculadas (I) ou não inoculadas (NI) com Glomus clarum em solo não esterilizado. * Efeito significativo a $5 \%$ pelo teste Tukey. Ingá - Inga laurina; Jatobá - Hymenaea courbaril;Caroba - Jacaranda cuspidifolia; Gabiroba Campomanesia cambessedeana; Baru - Dipterix alata; Chichá - Sterculia striata.

Figure 1 - Mycorrhizal colonization of arboreal species of the Cerrado biome as a function of inoculation with Glomus clarum (I) or noninoculation (NI) in unsterilized soil. * Significant effect at the 5\% level by the Tukey test. Ingá - Inga laurina; Jatobá - Hymenaea courbaril; Caroba - Jacaranda cuspidifolia; Gabiroba - Campomanesia cambessedeana; Baru - Dipterix alata; Chichá - Sterculia striata.

Para a matéria seca da parte aérea (MSPA) verificou-se efeito da interação entre a inoculação com FMA e a aplicação de $P$ ao solo apenas para a caroba. Para gabiroba, jatobá e ingá houve efeito significativo $(p \leq 0,05)$ isolado de um dos fatores, enquanto que baru e chichá não apresentaram efeito significativo para nenhum dos fatores estudados (Figura 3a e 3b).

A inoculação de Glomus clarum promoveu aumento na produção da matéria seca da parte aérea (MSPA) das plantas de gabiroba e ingá em 66 e 23\%, respectivamente, em relação às plantas não inoculadas (Figura 3a). Resultado semelhante foi encontrado por Zangaro et al. (2002), trabalhando com a espécie Campomanesia xanthocarpa O. Berg., do mesmo gênero da gabiroba, que foi inoculada com uma comunidade de FMAs nativos isolados da rizosfera de plantas arbóreas. Os autores observaram uma resposta de incremento da biomassa seca, pela inoculação, acima de $80 \%$, sendo este considerado muito alto.

Em relação aos efeitos da aplicação de $\mathrm{P}$ no solo (Figura 3b), pode-se verificar que o jatobá apresentou maior produção de MSPA no nível alto de $\mathrm{P}$, correspondendo a 

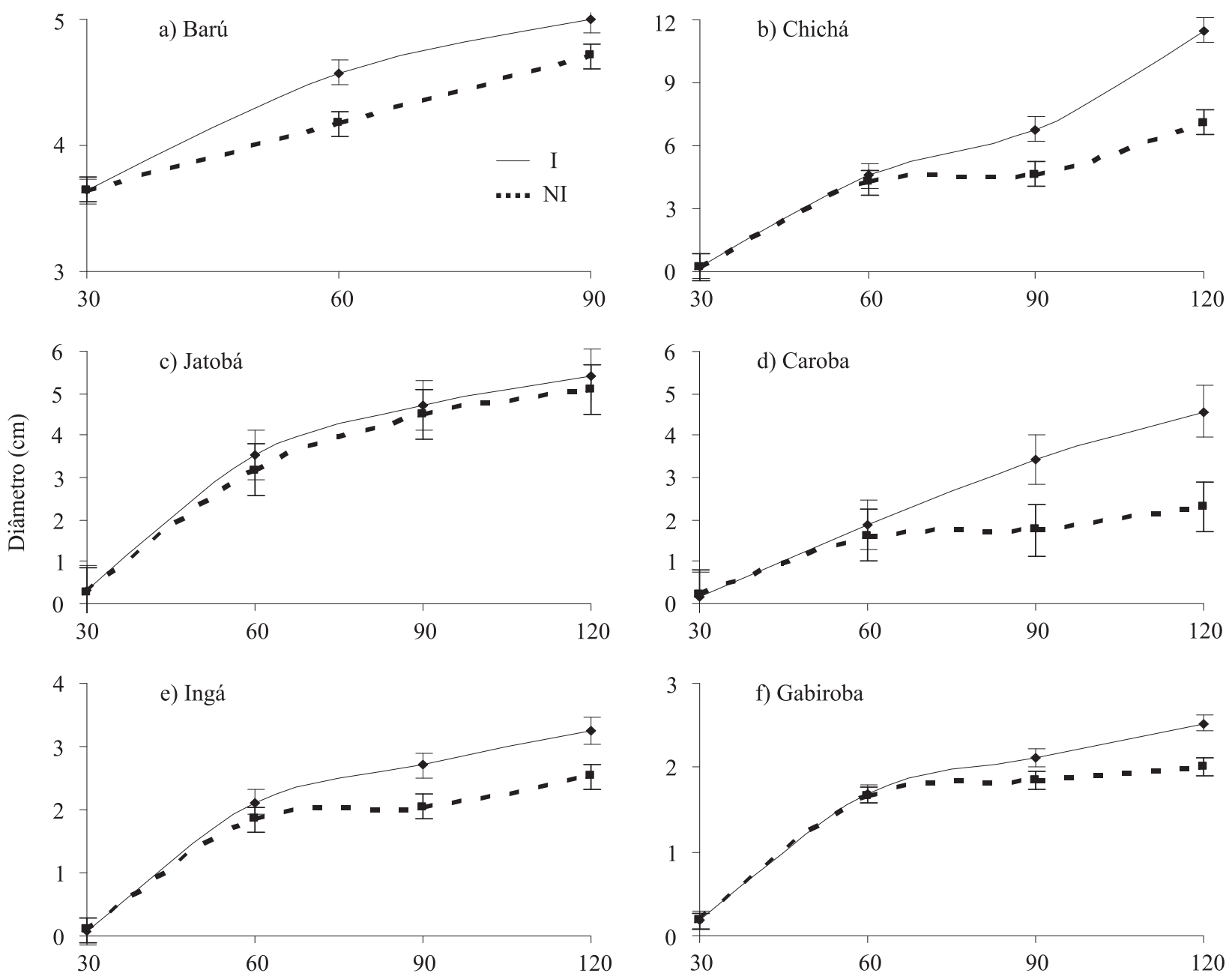

Dias após a germinação

Figura 2 - Diâmetro de caule na ausência (NI) e presença de inoculação (I) com Glomus clarum em espécies arbóreas do Cerrado. Barras indicam diferença significativa (DMS) entre os tratamentos dentro de cada época de coleta pelo teste de Tukey a 5\% de probabilidade. Ingá - Inga laurina; Jatobá - Hymenaea courbaril;Caroba - Jacaranda cuspidifolia; Gabiroba - Campomanesia cambessedeana; Baru - Dipterix alata; Chichá - Sterculia striata.

Figure 2 - Stem diameter without inoculation (NI) and with inoculation (I) with Glomus clarum in arboreal species of Cerrado. Bars indicate a significant difference (DMS) between treatments within each sampling period by the Tukey test at the 5\% probability level. Ingá - Inga laurina; Jatobá - Hymenaea courbaril; Caroba - Jacaranda cuspidifolia; Gabiroba - Campomanesia cambessedeana; Baru - Dipterix alata; Chichá - Sterculia striata.

um aumento de $15 \%$ em relação às plantas no solo com baixo $\mathrm{P}$, o que confirma alguns estudos já realizados com essa espécie arbórea (CARNEIRO et al., 1998; SAGGIN JÚNIOR, 1997; SIQUEIRA et al., 1998).

As plantas de caroba apresentaram efeito significativo para inoculação com FMA, para a aplicação de $\mathrm{P}$ e para a interação entre esses fatores na produção da
MSPA, evidenciando um sinergismo entre a aplicação de $\mathrm{P}$ e inoculação com Glomus clarum no crescimento dessa planta, observou-se um incremento na MSPA das plantas inoculadas e com alto $\mathrm{P}$ de $234 \%$, em relação às plantas não inoculadas em solo com baixo $\mathrm{P}$ na solução do solo (Figura 4a). Fato também observado na matéria seca de raízes (MSR), sendo que a combinação da aplicação de

Cerne, Lavras, v. 17, n. 3, p. 377-386, jul./set. 2011 


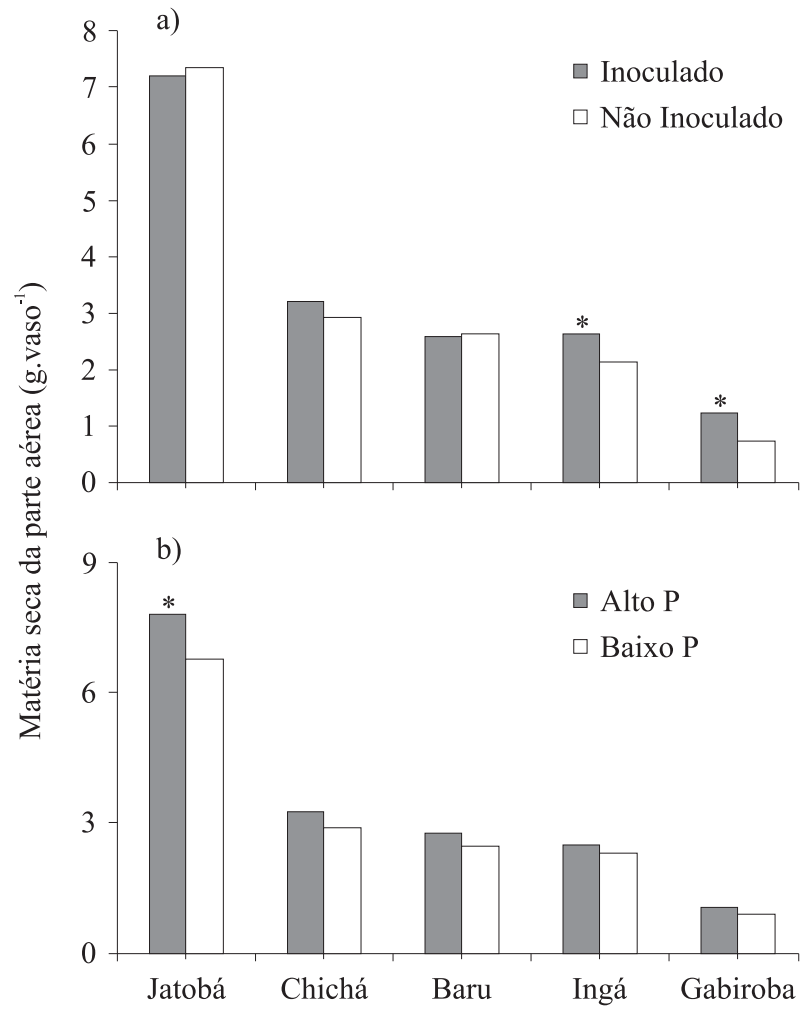

Figura 3 - Matéria seca da parte aérea de plantas do Cerrado em função da inoculação com Glomus clarum (a) e da aplicação de P no solo (b). * Efeito significativo pelo teste de Tukey a 5\% de significância. Ingá - Inga laurina; Jatobá - Hymenaea courbaril;Caroba - Jacaranda cuspidifolia; Gabiroba Campomanesia cambessedeana; Baru - Dipterix alata; Chichá - Sterculia striata.

Figure 3 - Shoot dry matter of Cerrado plants as a function of inoculation with Glomus clarum (a) and application of $P$ to the soil (b). * Significant effect by the Tukey test at the 5\% significance level. Ingá - Inga laurina; Jatobá - Hymenaea courbaril; Caroba - Jacaranda cuspidifolia; Gabiroba Campomanesia cambessedeana; Baru - Dipterix alata; Chichá - Sterculia striata.

alto Pe da inoculação com Glomus clarum proporcionaram aumento de $225 \%$ em relação às plantas em baixo $\mathrm{Pe}$ sem inoculação demonstrando um efeito sinérgico entre esses fatores (Figura 4b).

Para massa seca de raízes (MSR), as demais plantas arbóreas apresentaram efeito de apenas um dos fatores, exceto o ingá que não apresentou efeito de nenhum dos fatores estudados para a MSR (Tabela 2). O baru e o jatobá apresentaram efeito significativo apenas da aplicação de $\mathrm{P}$ ao solo, resultando num incremento da MSR de 9 e $13 \%$,
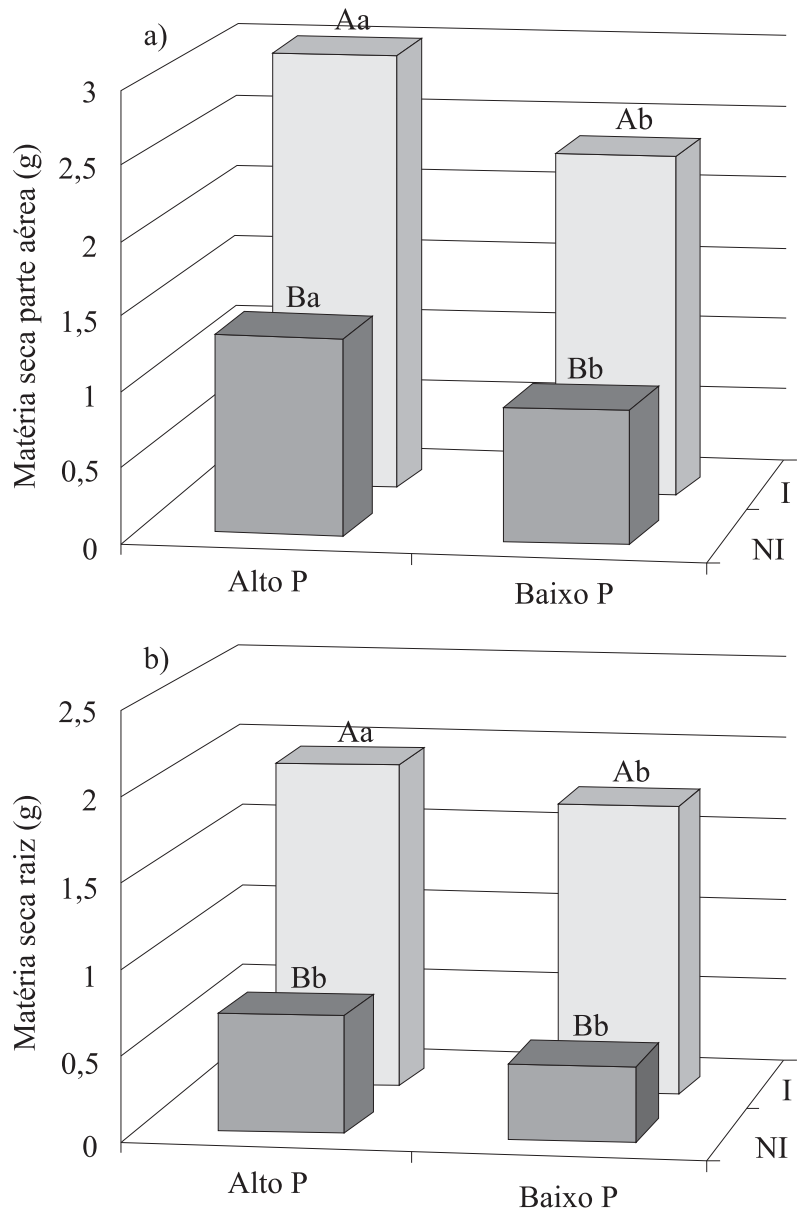

Figura 4-Matéria seca da parte aérea (a) e de raízes (b) da caroba (Jacaranda cuspidifolia) em alto e baixo P na solução do solo, inoculadas (I) e não inoculadas (NI) com Glomus clarum. Médias seguidas pela mesma letra, maiúscula comparam tratamento de inoculação e minúscula aplicação de $\mathrm{P}$, não diferem pelo teste de Tukey a 5\% de significância.

Figure 4 - Shoot dry matter (a) and root dry matter (b) of caroba (Jacaranda cuspidifolia) as a function of high and low $P$ concentrations in the soil solution, inoculated (I) and noninoculated (NI) with Glomus clarum. Means followed by the same letter, uppercase comparing inoculation and lowercase comparing $P$ application, do not differ by the Tukey test at the $5 \%$ significance level.

respectivamente, em solo com alto teor de $\mathrm{P}$ comparado ao solo com baixo teor de P (Tabela 2). A gabiroba e o chichá apresentaram efeito somente da inoculação micorrízica, resultando em um incremento da MSR pela inoculação de 130 e $50 \%$, respectivamente, em relação às plantas não inoculadas (Tabela 3). 
Tabela 2-Matéria seca de raízes de espécies arbóreas do Cerrado em baixo e alto P na solução do solo.

Table 2 - Root dry matter of arboreal species of Cerrado as a function of low and high $P$ concentrations in the soil solution.

\begin{tabular}{lcc}
\hline \multirow{2}{*}{ Espécie } & \multicolumn{2}{c}{ Fósforo na solução do solo } \\
\cline { 2 - 3 } & Baixo $\mathrm{P}$ & Alto $\mathrm{P}$ \\
\hline Gabiroba & $0,49 \mathrm{a}$ & $0,96 \mathrm{a}$ \\
Baru & $2,12 \mathrm{~b}$ & $2,41 \mathrm{a}$ \\
Jatobá & $3,80 \mathrm{~b}$ & $4,32 \mathrm{a}$ \\
Ingá & $1,54 \mathrm{a}$ & $1,42 \mathrm{a}$ \\
Chichá & $8,27 \mathrm{a}$ & $7,49 \mathrm{a}$ \\
\hline
\end{tabular}

Médias seguidas pela mesma letra na linha não diferem significativamente pelo teste de Tukey a $5 \%$ de probabilidade. Ingá - Inga laurina; Jatobá - Hymenaea courbaril; Gabiroba Campomanesia cambessedeana; Baru - Dipterix alata; Chichá - Sterculia striata.

Tabela 3 - Matéria seca de raízes de plantas arbóreas do Cerrado inoculadas (I) e não inoculadas (NI) com Glomus clarum.

Table 3 - Root dry matter of arboreal plants of Cerrado as a function of inoculation (I) and noninoculation (NI) with Glomus clarum.

\begin{tabular}{lccc}
\hline \multirow{2}{*}{ Espécie } & $\mathrm{I}$ & $\mathrm{NI}$ & $\begin{array}{c}\text { Resposta à } \\
\text { inoculação* }\end{array}$ \\
\cline { 2 - 4 } & \multicolumn{2}{c}{ g planta-1 $^{-1}$} & $\%$ \\
\hline Gabiroba & $1,01 \mathrm{a}$ & $0,44 \mathrm{~b}$ & 56 \\
Baru & $2,67 \mathrm{a}$ & $2,09 \mathrm{a}$ & 22 \\
Jatobá & $4,16 \mathrm{a}$ & $3,96 \mathrm{a}$ & 25 \\
Ingá & $1,64 \mathrm{a}$ & $1,32 \mathrm{a}$ & 18 \\
Chichá & $9,45 \mathrm{a}$ & $6,31 \mathrm{~b}$ & 33 \\
\hline
\end{tabular}

Médias seguidas de mesma letra nas linhas não diferem significativamente pelo teste de Tukey a $5 \%$ de probabilidade. *: $100[(\mathrm{X}-\mathrm{Y}) / \mathrm{X}]$, onde $\mathrm{X}$ é a massa da planta inoculada e Y a massa da planta não inoculada. Ingá - Inga laurina; Jatobá - Hymenaea courbaril; Gabiroba - Campomanesia cambessedeana; Baru Dipterix alata; Chichá - Sterculia striata.

Considerando a matéria seca total, a caroba e a gabiroba apresentaram consistente resposta positiva à inoculação com Glomus clarum, nos dois níveis de P na solução do solo, demonstrando que a prática da inoculação com esse fungo pode ser eficiente na promoção do crescimento e que estas plantas apresentam uma elevada dependência micorrízica, pois mesmo com alto $\mathrm{P}$ disponível no solo, ainda apresentaram-se responsivas à inoculação.
Em um programa de revegetação, o sucesso é maior quando se utilizam mudas de boa qualidade, mas, principalmente, mudas que apresentam elevada produção de raízes, o que auxilia seu estabelecimento em campo. Todas as plantas avaliadas apresentaram, em valores absolutos, sistema radicular mais pesado quando foram inoculadas com FMA, variando de $18 \%$ para o ingá a $69 \%$ para a caroba quando comparados à ausência de inoculação com FMA. Além disso, para a caroba, a inoculação com FMA associada à aplicação de $\mathrm{P}$, em nível alto na solução do solo, proporciona maior crescimento inicial, permitindo um menor tempo de permanência dessas mudas no viveiro e, possivelmente, menor taxa de replantio em campo. Fato similar foi observado no estudo de Carneiro et al. (2004) que demonstraram os efeitos benéficos da inoculação com FMA e da aplicação de P no crescimento inicial e, posteriormente, na taxa de sobrevivência em campo, de plantas de embaúba.

Já, o jatobá e o baru foram responsivos somente à aplicação de $\mathrm{P}$, não apresentando respostas a inoculação com Glomus clarum na fase de formação das mudas, além de apresentaram menor percentual de colonização micorrízica (Figura 1). Plantas que não respondem à inoculação micorrízica em condição de baixo fósforo na solução do solo possivelmente apresentam outra estratégia de obtenção de nutrientes para suportar seu crescimento (CHAPIN, 1980). No caso do jatobá e do baru, esta estratégia pode ter sido a obtenção de nutrientes das reservas de suas sementes, pois ambas possuem sementes muito grandes (Tabela 1). Allssop e Stock (1995) propuseram que mudas de espécies arbóreas com grandes reservas nas sementes têm nutrientes suficientes para o início do crescimento não necessitando da simbiose com fungos micorrízicos.

Os estudos de Pasqualini et al. (2007), Siqueira et al. (1998) e Zangaro et al. (2005) mostraram que o peso da semente apresentou correlação alta, negativa e significativa em relação à resposta à inoculação com FMA. Este fato também foi confirmado no estudo conduzido por Saggin Júnior (1997) com plantas de jatobá e outras espécies de sementes grandes, encontrando uma redução nos níveis de $\mathrm{P}$ nos tecidos vegetais com o tempo de crescimento, o que associou ao esgotamento das reservas nutricionais. Por outro lado, a caroba e a gabiroba possuem sementes pequenas (pequeno peso) e a inoculação micorrízica foi eficiente em promover o crescimento dessas plantas (Tabela 1).

Cerne, Lavras, v. 17, n. 3, p. 377-386, jul./set. 2011 
Na sucessão ecológica em um ecossistema florestal, as espécies arbóreas têm papel de pioneiras, secundárias ou clímax. Embora essa classificação das espécies não seja rígida, o papel que as espécies assumem na sucessão parece influenciar a sua resposta à inoculação micorrízica na fase de mudas. No presente estudo, as espécies pioneiras, ingá, gabiroba e caroba, apresentaram maiores respostas à inoculação micorrízica que, quando comparadas ao jatobá (espécie clímax), chichá e baru (espécies secundárias). Essa tendência de maior resposta das espécies pioneiras é relatada em vários outros estudos com espécies arbóreas e arbustivas no Brasil (CARNEIRO et al., 1998; SAGGIN JUNIOR, 1997; SIQUEIRA et al., 1998; ZANGARO et al., 2003). Segundo Siqueira et al. (1998), espécies pioneiras são altamente responsivas à inoculação com fungos micorrízicos arbusculares, enquanto as espécies clímax apresentam baixa ou, em alguns casos, como o próprio jatobá, nenhuma resposta a inoculação com FMA, durante os estágios iniciais de formação de mudas. Resultados obtidos por Zangaro et al. (2003) apontaram que as espécies pioneiras foram, em torno de $90 \%$, mais responsivas quando submetidas à inoculação com FMA, enquanto para as espécies clímax não passaram de $20 \%$.

Essa maior resposta à inoculação apresentada pelas espécies pioneiras, em relação às espécies clímax, pode estar relacionada à menor reserva de nutrientes nas sementes, como já discutido, mas pode também estar associada ao fato de que essas espécies, geralmente, apresentam uma alta velocidade de crescimento, o que leva a necessidade de rápido e intenso influxo de nutrientes, possivelmente suprido pela micorriza (SIQUEIRA et al., 1998; ZANGARO et al., 2003). Além disso, espécies pioneiras apresentam maior volume do sistema radicular, principalmente de raízes secundárias e terciárias como observado no estudo conduzido por Pasqualini et al. (2007), o que pode favorecer a colonização micorrízica.

Os fungos micorrízicos arbusculares possuem papel chave na recuperação/revegetação de áreas degradadas, pois proporcionam às plantas que se associam maior adaptabilidade ao ambiente, tornando-as mais competitivas (CARNEIRO et al., 1998; FLORES-AYLAS et al., 2003). Os resultados obtidos com as plantas de jatobá e caroba são confirmados em outros estudos já desenvolvidos por Carneiro et al. (1998), Saggin Júnior (1997) e Zangaro et al. (2002). Os resultados obtidos no presente estudo são de extrema importância para dar suporte a outras pesquisas cujo enfoque seja a produção de mudas de elevada qualidade, destinadas aos programas de revegetação.

\section{CONCLUSÕES}

A caroba (Jacaranda cuspidifolia), a gabiroba (Campomanesia cambessedeana) e o chichá (Sterculia striata) foram consideradas micotróficas.

A inoculação com Glomus clarum proporcionou incremento na colonização micorrízica em raízes de gabiroba (Campomanesia cambessedeana), baru (Dipterix alata), jatobá (Hymenaea courbaril), ingá (Inga laurina) e caroba (Jacaranda cuspidifolia), sendo apenas o chichá (Sterculia striata) e o ingá (Inga laurina) que apresentaram alta colonização micorrízicas pelos fungos indígenas do solo.

Mudas de caroba (Jacaranda cuspidifolia), gabiroba (Campomanesia cambessedeana), ingá (Inga laurina) e chichá (Sterculia striata) apresentaram resposta positiva em crescimento à inoculação com Glomus clarum, havendo incremento no diâmetro do caule e na matéria seca da parte aérea ou de raízes.

Mudas de jatobá (Hymenaea courbaril) e baru (Dipterix alata) responderam em crescimento apenas à aplicação de fósforo no solo com maior produção de matéria seca de parte aérea ou de raízes.

Mudas de caroba (Jacaranda cuspidifolia) apresentaram efeito sinérgico da inoculação de Glomus clarum e da aplicação de $\mathrm{P}$, apresentando produção de matéria seca de parte aérea e de raízes superior quando na presença de ambos os fatores.

Para produção de mudas de qualidade de caroba (Jacaranda cuspidifolia), gabiroba (Campomanesia cambessedeana), ingá (Inga laurina) e chichá (Sterculia striata) recomenda-se a inoculação com Glomus clarum conjuntamente com a fertilização do solo com P e para o jatobá (Hymenaea courbaril) e baru (Dipterix alata), apenas aplicação de $\mathrm{P}$ ao solo.

\section{AGRADECIMENTO}

Os autores agradecem ao $\mathrm{CNPq}$, pelo apoio financeiro ao projeto.

\section{REFERÊNCIAS}

ALLSSOP, N.; STOCK, W. D. Relationship between seed reserves, seedlings growth and mycorrhizal responses en 14 related shrubs (Rosideae), from a low nutrient environment funct. Bristish Ecological Society, London, v. 9, p. 248-254, Jan. 1995.

Cerne, Lavras, v. 17, n. 3, p. 377-386, jul./set. 2011 
CARNEIRO, M. A. C.; SIQUEIRA, J. O.; DAVIDE, A. C. Fósforo e inoculação com fungos micorrízicos arbusculares no estabelecimento de mudas de embaúba (Cecropia pachystachya Trec). Pesquisa Agropecuária Tropical, Goiânia, v. 34, n. 3, p. 119-125, nov. 2004.

CARNEIRO, M. A. C.; SIQUEIRA, O. J.; MOREIRA, F. M. S.; CARVALHO, D.; BOTELHO, S. A. Micorriza arbuscular em espécies arbóreas e arbustivas nativas de ocorrência no sudeste do Brasil. Cerne, Lavras, v. 4, n. 1, p. 129-144, dez. 1998.

CHAPIN, F. S. The mineral nutrition of wild plants. Annual Review of Ecology and Systematics, Palo Alto, v. 11, p. 233260, Nov. 1980.

FLORES-AYLAS, W. W.; SAGGIN-JÚNIOR, O. J.; SIQUEIRA, J. O.; DAVIDE, A. C. Efeito de Glomus etunicatum e fósforo no crescimento inicial de espécies arbóreas em semeadura direta. Pesquisa Agropecuária Brasileira, Brasília, v. 38, n. 2, p. 257-266, fev. 2003.

FRANCO, A. A.; DIAS, L. E.; FARIA, S. M. de; CAMPELLO, E. F. C.; SILVA, E. M. R. da. Uso de leguminosas florestais noduladas e micorrizadas como agentes de recuperação e manutenção da vida do solo: um modelo tecnológico. In: ESTEVES, F. A. (Ed.). Oecologia brasiliensis: estrutura, funcionamento e manejo de ecossitemas brasileiros. Piracicaba: ESALQ, 1995. p. 459-467.

GERDEMANN, J. W.; NICOLSON, T. H. Spores of mycorrhizal Endogone species extracted from soil by wet sieving and decanting. Transactions of the British Mycological Society, London, v. 46, p. 235-244, June 1963.

GRACE, C.; STRIBLEY, D. P. A safer procedure for routine staining of vesicular-arbuscular mycorrhizal fungi. Mycological Research, Amsterdam, v. 95, n. 10, p. 11601162, Oct. 1991.

HABTE, M.; MANJUNATH, A. Categories of vesiculararbuscular mycorrhizal dependency of hos species.

Mycorrhiza, Heidelberg, v. 1, n. 1, p. 3-12, Sept. 1991.

JORDAN, C. F. Nutrient cycling processes and tropical forest management. In: GOMEZ-POMPA, A.; WHITMORE, T. C.; HADLEY, M. (Ed.). Rain forest regeneration and management. Paris: The Parthenon, 1991. p. 159-179.
KOSKE, R. E.; GEMMA, J. N. A modified procedure for staining roots to detect VA mycorrhizas. Mycological Research, Amsterdam, v. 92, n. 4, p. 486-488, June 1989.

MCGONIGLE, T. P.; MILLER, M. H.; EVANS, D. G.; FAIRCHILD, G. L.; SWAN, J. A. A new method which gives an objective measure of colonization of roots by vesiculararbuscular mycorrhizal fungi. New Phytologist, Oxford, v. 115, n. 3, p. 495-501, July 1990.

MOREIRA, F. M. S.; SIQUEIRA, J. O. Microbiologia e bioquímica do solo. Lavras: UFLA, 2006. 729 p.

PASQUALINE, D.; UHLMANN, A.; STURMER, S. L. Arbuscular mycorrhyzal fungal communities influence growth and phosphorus concentration of woody plants species from the Atlantic rain forest in South Brazil. Forest Ecology and Management, Amsterdam, v. 245, n. 1/3, p. 148-145, June 2007.

PLENCHETTE, C.; FORTIN, J. A.; FURLAN, V. Growth responses of several plants species to mycorrhizae in a soil of moderate P-fertility I: mycorrhizal dependency under fied conditions. Plant and Soil, The Hague, v. 70, n. 2, p. 199-209, Oct. 1983.

SAGGIN JÚNIOR, O. J. Micorrizas arbusculares em mudas de espécies arbóreas nativas do Sudeste Brasileiro. 1997. 120 p. Tese (Doutorado em Agronomia) - Universidade Federal de Lavras, Lavras, 1997.

SIQUEIRA, J. O.; CARNEIRO, M. A. C.; CURI, N.; SILVAROSADO, S. C. da; DAVIDE, A. C. Mycorrhizal colonization and mycotrophic grouth of native Woody species as related to successinal groups in Southeastern Brasil. Forest Ecology Management, Amsterdam, v. 107, n. 1/3, p. 241-252, Aug. 1998.

SIQUEIRA, J. O.; SAGGIN JÚNIOR, O. J. Dependency on arbuscular mycorrhizal fungi and responsiveness of some Brazilian native woody species. Mycorrhiza, Heidelberg, v. 11, p. 245-255, Dec. 2001.

ZANGARO, W.; NISHIDATE, F. R.; CAMARGO, F. R. S.; ROMAGNOLI, G. G.; VANDRESSEN, J. Relationships among arbuscular mycorrhizas, root morphology and seedling growth of tropical native woody species in southern Brazil. Journal of Tropical Ecology, London, v. 21, n. 5, p. 529-540, Oct. 2005 .

Cerne, Lavras, v. 17, n. 3, p. 377-386, jul./set. 2011 
ZANGARO, W.; NISIZAKI, S. M. A.; DOMINGOS, J. C. B.; NAKANO, E. M. Micorrizas arbuscular em espécies arbóreas nativas da bacia do rio Tibagi, Paraná. Cerne, Lavras, v. 8, n. 1, p. 77-87, mar. 2002.
ZANGARO, W.; NISIZAKI, S. M. A.; DOMINGOS, J. C. B.; NAKANO, E. M. Mycorrhizal response and sucessional status in 80 woody species from South Brasil. Journal of Tropical Ecology, London, v. 19, n. 2, p. 315-324, Mar. 2003.

Cerne, Lavras, v. 17, n. 3, p. 377-386, jul./set. 2011 